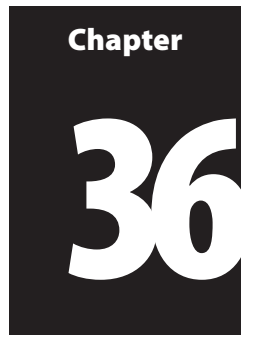

\title{
Refugees, Asylum and Mental Health in the UK
}

\author{
Peter Hughes and Cornelius Katona
}

Of troubles none is greater than to be robbed of one's native land.

Euripides, $431 B C^{1}$

\section{Introduction}

In 2007, there were 11.4 million refugees worldwide of which the UK had just 3 per cent. This was about 300,000 people or 0.5 per cent of the UK population. ${ }^{2}$

The story in the UK is one of both welcome and rejection. ${ }^{3}$ It brings out the best and the worst of society. Refugees are traumatised by not only the experiences of their homeland and their journey but also settling in the UK. ${ }^{4}$ They have been disbelieved, accused of embellishing their stories to get asylum and subjected to racism. ${ }^{5}$

Both authors could retell gruelling accounts of torture, murder and humiliation. This is not what we want to do. We want to celebrate the resilience of refugees. We therefore dedicate this chapter to all those who came to the UK seeking protection and who have made a life in the UK against the odds.

\section{Refugees, Psychiatrists and Mental Health Services}

A refugee is defined as a person who is outside of their country of origin and who has a wellfounded fear of returning there on the grounds that they may be persecuted because of race, religion, nationality, membership of a particular social group or political opinion or affiliation. ${ }^{6}$ Refugees are a marginalised and isolated group. ${ }^{7}$ We remember their humanity and that they are normal people who have had to face extraordinary circumstances. They are us.

Refugees have been recognised as entitled to international protection. Asylum seekers are waiting for their refugee status to be established legally. Such waiting causes a great deal of anxiety. ${ }^{8}$

The number of refugees to the UK has steadily diminished since $1960 .{ }^{9}$ Both before this period and in the early years covered, the UK had generally been a welcoming place in spite of the views of the hostile minority exemplified by the 'Rivers of Blood' speech by Enoch Powell in 1968. ${ }^{10}$

The story of refugees' mental health during the period covered in this book was less about theoretical arguments regarding psychiatric diagnosis and more about their struggles with the Home Office, getting food on the table, having a place to live and finding acceptance and work. ${ }^{11}$ All too many refugees have told us that it was neither the problems they faced back home country nor their journey that caused them the greatest difficulty but rather the 
challenges of surviving day-to-day in a new country facing the machinery of government which seemed to be against them. ${ }^{12}$

Past mental health research has been disproportionately focused on post-traumatic stress disorder (PTSD) as a diagnosis. ${ }^{13}$ The focus has broadened in more recent years. Refugees are now known to have a higher rate and wider range of mental health problems as well as experiencing psychosocial stress. ${ }^{14}$ Their overall risk of mental disorder is increased fivefold and may also increase with age - particularly in the case of depression and anxiety. ${ }^{15}$

Working as a clinician with refugees is more often about writing supportive letters for their housing difficulties and reports for the Home Office in the context of their immigration claims rather than about identifying and treating their mental health problems. Their story is tied up with politics and resources. They have been at the bottom rung of the society they have joined and are affected disproportionately when economies are stretched. ${ }^{16}$ This is also when racism increases. Refugee women and children are particularly marginalised and vulnerable. ${ }^{17}$

We avoid the word trauma as this tends to perpetuate the narrative of victimhood. ${ }^{18} \mathrm{We}$ want to celebrate refugees as potential or actual contributors to the society they have joined rather than as victims. Throughout recent history, the UK has benefited overwhelmingly (economically, socially and culturally) from the contribution of refugees. ${ }^{19}$ To take one obvious example, Sigmund Freud arrived in the UK as a refugee from Austria in 1938 and lived there until his death in $1939 .{ }^{20}$ Anna Freud, his daughter, was a pioneer in child mental health in what is now called the Anna Freud Centre in London. Lucian Freud, his grandson, was one of the greatest post-war British painters.

During the period in question, considerable development took place of organisations to support refugees and asylum seekers. ${ }^{21}$ There has been a developing balance between specialised refugee services and mainstream (publicly funded) health and social care services. Interpreters and mediators both of language and of culture have been crucial and their role cannot be overstated. ${ }^{22}$

\section{Origins}

Britain is an island that used to be joined to Europe by a land bridge until 10,000 years ago. ${ }^{23}$ The first recorded arrivals were farmers from south-east Europe. There have been waves of arrivals since - the Romans in 55 BC, the Anglo-Saxons from Europe in the fifth century AD, the Vikings in $\mathrm{AD} 789$, the Normans in the eleventh century. ${ }^{24}$ There has been uncertainty about which of them were escaping persecution and were therefore refugees. The Huguenots - French protestants who fled French persecution in the seventeenth century were a clear example of refugees. Since then, there have been successive waves such as a quarter of a million Irish who fled the potato famine since the $1850 \mathrm{~s} .{ }^{25}$ In the early twentieth century, 120,000 Jewish people arrived, fleeing from persecution ('pogroms') in eastern Europe and Russia. ${ }^{26}$

The Second World War transformed UK policy due to the increased post-war need for labour. Volunteers were recruited from displaced camps in Europe to come to the UK. After the war, the largest refugee group were from Poland. By 1950, 85,000 people had arrived from Europe. Migrants also came from former colonial countries in the 1950s, again to meet labour shortage. There was a substantial influx of Hungarians fleeing persecution after the 1956 uprising against the communist regime. ${ }^{27}$ 
Table 36.1 Waves of migration: main waves $1960-2010^{28}$

\begin{tabular}{|c|c|c|c|}
\hline $\begin{array}{l}\text { Years of arrival } \\
\text { in UK }\end{array}$ & Groups & $\begin{array}{l}\text { Approximate figures } \\
\text { of arrivals in UK }\end{array}$ & Reason for flight \\
\hline $1960 s$ & Kenya Asians & Unknown figure & Conflict \\
\hline 1972 & Ugandan Asians & 30,000 & $\begin{array}{l}\text { Forced } \\
\text { deportation }\end{array}$ \\
\hline 1974 & $\begin{array}{l}\text { Chilean/ } \\
\text { Argentinian }\end{array}$ & 5,000 & $\begin{array}{l}\text { Political } \\
\text { oppression }\end{array}$ \\
\hline $1974-5$ & $\begin{array}{l}\text { Cypriots (mainly } \\
\text { Greek) }\end{array}$ & 10,000 & War \\
\hline 1979 & Vietnamese & 16,000 & War \\
\hline 1980s and 1990s & Tamils of Sri Lanka & 100,000 & War \\
\hline 1983 & Iranians & 8,000 & War/revolution \\
\hline 1990s & $\begin{array}{l}\text { Refugees from } \\
\text { Bosnian/ } \\
\text { Kosovo war }\end{array}$ & 5,000 & War \\
\hline $2000 s$ & Sierra Leone war & 17,000 & War \\
\hline
\end{tabular}

There have been several thousand asylum seekers each year during the period covered in this book (see Table 36.1), with about half having their application granted. The influx has reflected geopolitical turmoil. Examples of this include the influx of Asians from Kenya in the 1960s and of Czech refugees after the 1968 uprising. In 1972, 30,000 Ugandan Asian refugees arrived (mainly whole families), following their expulsion by Idi Amin. Several of the new arrivals had relatives already living in the UK. They spoke English and had British passports. Their arrival was planned. They moved to places where there was more housing capacity and assimilated relatively easily. The Cypriots (mainly Greek) of 1973 and 1974 similarly came as whole families with previous UK connections. As with the Asians from Uganda, many already had family connections in the UK. ${ }^{29}$

In 1974, political opponents of the Chilean and Argentinian dictatorships came to the UK. In 1979, the influx of 16,000 Vietnamese - mainly boat people from the Hong Kong camps - began. Some of the people granted protection in the UK had come as students but could not return when the situation in their country changed. These include many Iranians who were in the UK at the time of the 1983 Islamic Revolution. ${ }^{30}$ In the early 2000s, many citizens of Sierra Leone left the civil war to come to the UK. About 100,000 Tamil people live in the UK - most of whom because of the prolonged Sri Lankan civil war. $^{31}$

Many refugees came to specific areas of the UK to be within their own communities. Though this brought risks of ghettoisation, the growth of migrant communities also facilitated group support and the preservation of cultural identity. There are, for example, well-defined Vietnamese, Tamil and Somali communities in London. ${ }^{32}$

Although the government has been keen to encourage integration, ${ }^{33}$ there has been an ongoing tension between integration and multiculturalism. ${ }^{34}$ Only a small number of refugees moved from densely populated areas such as London to less populated areas. 
Most of those making such moves were males in their twenties or thirties; they represent only about $10-20$ per cent of refugees. ${ }^{35}$

There have been services focused on particular groups - for example, Polish, Vietnamese, Irish and Somali. However, this approach has changed to one of mainstreaming all into standard NHS services regardless of origin. There are some charitable organisations that support particular communities. For example, the Vietnamese mental health project helps people from their community in accessing health care. ${ }^{36}$

\section{Reception}

There are more than 190 different nationalities represented in the UK - reflective of its complex global history, including the arrival of migrants and refugees. They include many of the people who staff our NHS today. The history of refugees in the UK parallels the experience in other developed nations - a balance of official/community support and scepticism. ${ }^{37}$ The tensions between embracing multiculturalism and encouraging integration are exemplified on the one hand by the development of specialised culture-specific services and on the other by encouraging incorporation into mainstream ones. ${ }^{38}$ Irrespective of how the host society manages that balance, what is common in the refugee experience is the exposure to poverty and discrimination, compounding an existential loss of one's homeland. ${ }^{39}$

New arrivals' hope for the future is linked to their application for asylum and their expectation of welcome and protection. However, simply a mention of 'Lunar House' in Croydon (the headquarters of 'UK Visas and Immigration', a division of the Home Office in the UK where most new arrivals seeking asylum attend) will provoke a marked emotional reaction in refugees. This is where they wait for hours to process their papers. It symbolises a loss of control over their lives and of hope. Many reported experiencing scepticism and a dehumanising approach. They carry a substantial baggage of fear - of not being believed and of being deported. Any inconsistency may lead to them being discredited. In consequence, they may be suspicious of state and voluntary organisations. ${ }^{40}$

The UK is bound by two international legal instruments in its dealings with those seeking and/or granted asylum - the UN Refugee Convention of 1951 and the Protocol of 1967..$^{41}$ These established basic minimum standards for refugees and asylum seekers and enshrined the right to asylum and not to be forcibly returned if such return was to result in further state-sponsored ill treatment ('refoulement'). Additionally, the Human Rights Act 1998 provides a framework for protection of those who fall outside the Refugee Convention but whose human rights would be jeopardised by a return to their home country.

In parallel with the development of a legislative framework of protection, the history of migration and immigration in the UK is of a legal framework of increasing restrictions on entry to and domicile in the UK. The Aliens Act of 1905 and 1920 as well as successive immigration acts since 1968 have restricted the borders. From 1929 to 1939, more obstacles were put in place. Within the provisions of the 1971 Immigration Act, people can be prevented from coming to the UK based on a psychiatric diagnosis. ${ }^{42}$

There are also language, cultural and informational barriers to accessing health services. ${ }^{43}$ Refugees themselves often prioritise their basic needs and status before being able to address psychological issues. Health services must be aware of culture and of the intrinsic power imbalance. The agendas between refugee and health worker may be mismatched in that the mental health worker wants to focus on mental health issues while 
refugees may fear being disbelieved or deported and therefore try to present information in a way that might be acceptable to the health worker and perceived as 'normal'. As a result, their accounts may appear coached and embellished, or they may appear inscrutable or ungrateful. $^{44}$

Refugees give consistent stories of their stressful experiences and the situation impeding them. Recounting stories itself can be experienced as traumatic and may be met with disbelief. There are a minority of stories that have been 'coached'. ${ }^{45}$ Even where this is the case (e.g. in survivors of human trafficking who have been told what to say by their traffickers and threatened with retribution to themselves or their families if they tell the truth), this does not detract from the intrinsically stressful nature of that person's experience. It is, however, challenging for UK mental health professionals to get through these defences and to be sufficiently aware of our own prejudices and countertransference. In response to this imbalance, specific refugee and trauma-focused services were developed. There remain tensions between mainstream and specialist as well as between traumafocused and resilience-based psychological interventions. ${ }^{46}$

\section{Refugee Experience}

Being a refugee/migrant is intrinsically stressful. ${ }^{47}$ There is an initial relief. This is followed by anxiety, depression, guilt, anger and fear of being returned, compounded by feelings of injustice. There is a culture shock which is increased by language difficulties. ${ }^{48}$ The resilience of refugees is related to their experience before leaving their home country, their journey and the opportunities they have (or have not) been given to assimilate in UK. They may have what has been termed 'survivor syndrome', where they feel guilty about leaving behind their home country. ${ }^{49}$ The asylum process also causes distress with protracted periods of uncertainty. Those who have pre-existing mental health issues may be more vulnerable, or problems may manifest later in life. ${ }^{50}$ The experience of being a refugee has led people to become depressed. ${ }^{51}$ Common clinical symptoms in refugees include sleep problems, restlessness, inertia and somatisation (headaches, dyspepsia and 'cardiac'-type symptoms). ${ }^{52}$

There has been an excess focus on mental health problems rather than on social adversity. Meeting basic needs has been shown to reduce psychiatric morbidity. ${ }^{53}$ Mental health problems may also be missed or misidentified as PTSD. ${ }^{54}$ There may be an incentive to diagnose PTSD to fit with the narrative of the asylum process. This can miss other diagnoses or pathologise normal distress. For example, one study in the Somali community showed that more than a third had a mental disorder but that PTSD was present in just 14 per cent. ${ }^{55}$ There can be cross-cultural aspects to psychosis which can lead to a barrier to treatment or inappropriate treatment. Hyperarousal, anger or silence may be misinterpreted as paranoia.

Understanding a refugee's culture is crucial. Unaccompanied minors, single men, women and frail elderly are all particularly vulnerable. ${ }^{56}$ Gaining employment is a key factor especially for men. ${ }^{57}$ Being able to work is an important theme for refugees' wellbeing. ${ }^{58}$

Refugees and other migrants face obstacles in accessing health services, housing, employment, education and acceptance by the host community. ${ }^{59}$ The longer the period of adjustment, the greater the increased risk of mental health difficulties. ${ }^{60}$ They also feel more distressed when they hear of events back home. ${ }^{61}$ 
One of the authors $(\mathrm{PH})$ reflects on someone he saw during this period:

A young man from Central Africa. He had torture wounds. He had the stress of his Home Office asylum application. He had poor sleep, depression. He was referred for 'depression' but the problem was poverty and isolation. His past experiences were just that - the past relative to his current struggles. Treatment consisted of referring him to the hospital football team. This taught me that the role of the psychiatrist stretches us to think beyond the narrow diagnostic perspective. ${ }^{62}$

\section{Women Refugees}

Women refugees are particularly vulnerable. ${ }^{63}$ They have often been exposed to sexual and gender-based violence. ${ }^{64}$ Adjustment is particularly difficult for those separated from their families and their children. ${ }^{65}$ Traditional roles of childrearing and household chores may be affected by the refugee experience, with women disproportionately affected. Women have also been found to be less likely to be able to access services or have a social network than men. ${ }^{66}$ Some women do not feel comfortable talking to a male health worker. They report that they would fear just being given medication for a mental health problem. ${ }^{67}$

Among women refugees, there have been some myths that they should not and could not access primary health care and in turn all health services. It is unclear whether these arose out of suspiciousness or from a misconstrued gender belief. After sexual and gender-based violence, there can be anxiety, sexual difficulties and concerns about fertility. ${ }^{68}$ When a woman can return to a previous role as a mother this can, however, be protective. The importance of such family reunion (often very challenging to achieve) cannot be overestimated.

\section{Interventions}

The authors have been involved in interventions in third-sector settings such as the Helen Bamber Foundation and the Vietnamese Mental Health project as well as in mainstream services. Whatever the context in which interventions are delivered, the key to good mental health is achievement of settled status and meeting basic needs. The unmet needs are the loss of one's past and the injustice. ${ }^{69}$

A report in 2007 describes different innovative treatments for refugees with mental health problems. ${ }^{70}$ These were started by refugees and were locally owned, which helped with their success. They included offering refugee women work, creative therapies, horticulture, crafts and psychological therapy. Mental health services have not been viewed as a support system by the women. Instead, there have been programmes for the mental health of various groups staffed by people from that community, ${ }^{71}$ for example Somali and Vietnamese.

\section{Employment}

Programmes of employment have been a key factor in refugee integration. ${ }^{72}$ However, until their asylum status is settled, most asylum seekers cannot work. Finding work is difficult even after refugee status has been granted. Refugee unemployment was 36 per cent in 2002 when the general UK rate was approximately 5 per cent. ${ }^{73}$ Many remain unemployed longterm in the UK even when they are technically able to work. ${ }^{74}$ The refugee integration and employment service was established in 2008 to help with this. ${ }^{75}$ 


\section{The Example of Vietnamese Refugees}

The Vietnamese diaspora to the UK began in the 1960s in different waves, including the boat people of the 1970s from Hong Kong camps. The Vietnamese struggled with a different culture and language. The stigma of mental illness was strong and symptoms were often concealed within the family. The old suffered from a loss of their role in their family and community. ${ }^{76}$ Young men did better, and women did better if they could resume a domestic role at home. The most common psychiatric disorders in this group were schizophrenia or depression, ${ }^{77}$ with the rate of schizophrenia 1.3 per cent higher than back in Vietnam. In the UK, the Vietnamese mental health project was set up to bridge the cultural gap, tackle stigma and work with families. Services included drop-in centres, advocacy and support in accessing mainstream services. The project provided a gateway from specialised to mainstream services.

\section{The Life and Work of Helen Bamber}

Helen Bamber (1925-2014), ${ }^{78}$ with whom one of the authors of this chapter (CK) had the privilege of working closely with towards the end of her long and distinguished life, had a career in human rights, working mainly but not exclusively with asylum seekers and refugees, which spanned the whole of the period covered in this book. This brief summary of her career, and the ethical principles that underpinned her work, draws both on published material and on CK's unpublished interviews with her.

People often ask me why I have spent most of my life concerned with the consequences of conflict and violence. The simple answer is 'why not?'. It is about the suffering of refugees. It is about the short life of compassion, how quickly it is born and how quickly it dies. It is about the stranger to whom we owe nothing. It is about how our society will be judged and how we discover our humanity. It is about love. ${ }^{79}$

In 1945, as a member of the British Jewish Relief Unit, Bamber entered the liberated concentration camp at Bergen-Belsen. ${ }^{80}$ In 1961, Bamber joined Amnesty International and, in 1974, she helped establish the Medical Group within Amnesty. In this role, she was instrumental in persuading the British Medical Association to establish a Working Party on Torture. During the 1970s and 1980s, she helped develop a framework for documenting torture and inhuman or degrading treatment and was active in campaigning against torture internationally. The groups on whom she focused included the 'disappeared' in Chile, victims of the political abuse of psychiatry in the Soviet Union and people 'interrogated' by the authorities during the Troubles in Northern Ireland.

Bamber also worked therapeutically with individual victims of such torture and ill treatment. In 1985, she founded the Medical Foundation for the Care of Victims of Torture (now Freedom from Torture). In 2005, she set up the Helen Bamber Foundation to work with survivors of a broader range of extreme human cruelty such as human trafficking, domestic violence and ill treatment because of gender or sexual orientation as well as with survivors of torture.

The conventional wisdom identifies Bamber's experiences of working in the newly liberated Bergen-Belsen concentration camp in 1945 as the main driver of her future work. However, as she explained to $\mathrm{CK}$, her journey into human rights started even earlier, as a Jewish child in London in the 1930s, witnessing fascist mobs and hearing Hitler's radio broadcasts. 
This is not to deny the importance of what Bamber witnessed in Bergen-Belsen. As she told CK,

I remember very clearly that there was one day in Belsen when some people ... were coming. They wanted some clothes, some provisions. And they were pretty aggressive and I said to one of the group, 'I really don't like that man very much'. And she said to me, 'We're not here to like people or not to like people. We're here for something quite different. $^{.81}$

Bamber often spoke of the necessity of 'bearing witness' to the crimes of humanity and of distinguishing between bystanders and active witnesses. In her own words,

sometimes I found it necessary to say to people who I knew were not going to live: 'You are giving me your testimony and I will hold it for you and I will honour it and I will bear witness to what has happened to you. ${ }^{82}$

Another of Bamber's guiding principles was that survival itself was not enough - what was needed was what she called 'creative survival'. She encouraged the survivors she worked with to take part in cultural and skill-building group activities that helped them develop identities beyond that of 'survivor' while also helping them to trust and respect each other and themselves.

Bamber remained angry and energised by that anger throughout her working life but she was also a consummate diplomat. She understood that dialogue was necessary even with people and systems with whom she remained angry - and that anger and sympathy could coexist. As she told CK,

in our relationship with decision makers here, we do find a certain sympathy. And that in many places there are people who do appear to understand. But the systems are not designed for understanding the questions people asked, the links that are not made in asking them questions.

\section{Conclusion}

Refugees have been coming to the UK for generations. The waves of refugee influx during the time period addressed in this volume reflected geopolitical turmoil during the time in question. The experience of the refugee has been intrinsically stressful with increased mental health problems. Refugees suffer from an increased rate of mental illness. This is particularly evident in women. ${ }^{83}$ It may take much longer to get a clear health history from a refugee. Clinicians need to be aware of culture and the refugee agenda, and follow-up may be more difficult. Refugees' access to mental health services has also been problematic. Mainstreaming was the main approach but some specialist services enhanced access during this time. Some specialist services also developed within the voluntary sector - such as Freedom from Torture and the Helen Bamber Foundation.

\section{Key Summary Points}

- We want to celebrate the resilience of refugees. We therefore dedicate this chapter to all those who came to the UK seeking protection and have made a life in the UK against the odds. 
- Past mental health work has been disproportionately focused on post-traumatic stress disorder (PTSD) as a diagnosis. ${ }^{84}$ This has improved in more recent years. Refugees are now known to have a higher rate and wider range of mental health problems as well as psychosocial stress.

- Refugees need their basic needs met as well as addressing mental health problems. Interventions that have helped have been social such as access to employment, ${ }^{85}$ combating discrimination and fostering inclusiveness. Resolving asylum uncertainty has been central to a reduction in mental health distress.

- The culture of the refugee cannot be underestimated in assessing and managing their health needs.

- One difficulty has been refugees' access to mental health services. Mainstreaming was the main approach but some specialist services enhanced access during this time. Some specialist services developed within the voluntary sector.

\section{Notes}

1. Euripides, Medea 653 (Tufts English edition), www.perseus.tufts.edu/hopper/text?doc+Perseus $\% 3$ Atext $\% 3$ A1999.01.0114\%3Acard\%3D645.

2. R. Baker, The Psychosocial Problems of Refugees. London: British Refugee Council and European Consultation on Refugees and Exiles, 1983.

3. Ibid.; D. Summerfield, Asylum seekers, refugees and mental health services in the UK. Psychiatric Bulletin (2001) 25: 161-3.

4. Baker, Psychosocial Problems of Refugees.

5. Summerfield, Asylum seekers.

6. Baker, Psychosocial Problems of Refugees.

7. Ibid.

8. International Rescue Committee, Migrants, asylum seekers, refugees and immigrants: What's the difference?, International Rescue Committee (website), 22 March 2019, www.rescue-uk.org/article/migrants-asylumseekers-refugees-and-immigrants-whats-difference? gclid=EAIaIQobChMI9am5kPS16gIVWuztCh3gMg1KEAAYAiAAEgLlIfD_BwE.

9. Ibid.

10. Enoch Powell's 'Rivers of blood' speech. The full text is available online: https://anth1001.files.wordpress.com /2014/04/enoch-powell_speech.pdf.

11. Baker, Psychosocial Problems of Refugees.

12. Ibid.

13. G. De Jirolamo and A. C. McFarlane, The epidemiology of PTSD: A comprehensive review of the international literature. In A. Marsella, M. J. Friedman, E. T. Gerrity and R. M. Scurfield, eds, Ethnocultural Aspects of Post-traumatic Stress Disorder, 33-86. Washington, DC: American Psychological Association, 2003; Summerfield, Asylum seekers.

14. Baker, Psychosocial Problems of Refugees.

15. Ibid.

16. Ibid.; Summerfield, Asylum seekers.

17. A. Ahmad and J. Smith, Humanitarian Action and Ethics. London: Zed Books, 2018, pp. 181-200; Baker, Psychosocial Problems of Refugees. 
18. Ahmad and Smith, Humanitarian Action and Ethics.

19. Baker, Psychosocial Problems of Refugees.

20. Ibid.

21. Ibid.

22. Ahmad and Smith, Humanitarian Action and Ethics; R. Tribe and N. Patel, Editorial special issue on refugees and asylum seekers. The Psychologist (2007) 20: 149-51.

23. H. Dillon and A. Smith, Life in the UK Test Handbook: 2019 Edition. London: Red Squirrel Publishers, 2019.

24. Ibid.

25. D. Bhugra, Migration and mental health. Acta Psychiatrica Scandinavica (2004) 109: 243-58.

26. Baker, Psychosocial Problems of Refugees.

27. Ibid.

28. Ibid.

29. Ibid.

30. Ibid.

31. R. Healey, Refugee employment experiences: The case of Tamil refugees in the UK. PhD thesis, University of Chester, 2010.

32. Baker, Psychosocial Problems of Refugees; De Jirolamo and McFarlane, The epidemiology of PTSD; Healey, Refugee employment experiences.

33. A. Ager and A. Strang, The Experience of Integration: A Qualitative Study of Refugee Integration in the Local Communities of Pollockshaws and Islington. Home Office Report No. 55/04, 2004.

34. A. Rogers and D. Pilgrim, A Sociology of Mental Health and Illness (5th ed.). Maidenhead: Open University Press.

35. K. Bhui, A. Abdi, M. Abdi et al., Traumatic events, migration characteristics and mental symptoms among Somali refugees. Social Psychiatry and Psychiatric Epidemiology (2003) 38: 35-43; De Jirolamo and McFarlane, The epidemiology of PTSD.

36. Healey, Refugee employment experiences; H. McColl and S. Johnson, Characteristics and needs of asylum seekers and refugees in contact with London Community Mental Health Teams. Social Psychiatry and Psychiatric Epidemiology (2006) 41: 789-95, https://doi.org/10.1007/s00127-006-0102-y.

37. Baker, Psychosocial Problems of Refugees; Summerfield, Asylum seekers.

38. Ager and Strang, The Experience of Integration.

39. Baker, Psychosocial Problems of Refugees.

40. Summerfield, Asylum seekers.

41. Baker, Psychosocial Problems of Refugees.

42. Ibid.

43. Ibid.

44. Summerfield, Asylum seekers.

45. Ibid.

46. Baker, Psychosocial Problems of Refugees.

47. Ibid.

48. Baker, Psychosocial Problems of Refugees.

49. Ibid. 
50. D. Patrick and P. J. D. Heaf, Long Term Effect of War Related Deprivation on Health: A Report on the Evidence. London: St Thomas's Hospital Medical School, 1981.

51. Baker, Psychosocial Problems of Refugees; Summerfield, Asylum seekers.

52. Ahmad and Smith, Humanitarian Action and Ethics; Baker, Psychosocial Problems of Refugees; D. Giacco, A. Matanov and S. Priebe, Providing mental healthcare to immigrants: Current challenges and new strategies. Current Opinion in Psychiatry (2014) 27: 282-8; McColl and Johnson, Characteristics and needs of asylum seekers and refugees.

53. K. Day and P. White, Choice or circumstance: The UK as the location of asylum application by Bosnian and Somali refugees. GeoJournal (2002) 56: 15-26; S. W. Turner, C. Bowie, G. Dunn, L. Shapo and W. Yule, Mental health of Kosovan Albanian refugees in the UK. British Journal of Psychiatry (2003) 182: 444-8.

54. Ahmad and Smith, Humanitarian Action and Ethics.

55. Day and White, Choice or circumstance.

56. Baker, Psychosocial Problems of Refugees.

57. Day and White, Choice or circumstance; Healey, Refugee employment experiences.

58. Baker, Psychosocial Problems of Refugees; Miller et al., The relative contribution of war experiences and exile-related stressors to levels of psychological distress among Bosnian refugees. Journal of Traumatic Stress (2002) 15: 377-87; Turner, Bowie, Dunn, Shapo and Yule, Mental health of Kosovan Albanian refugees.

59. Baker, Psychosocial Problems of Refugees; Giacco, Matanov and Priebe, Providing mental healthcare to immigrants; McColl and Johnson, Characteristics and needs of asylum seekers and refugees; S. Schaecter, A study of psychosis in female migrants. Medical Journal of Australia (1962) 2: 458-61.

60. Baker, Psychosocial Problems of Refugees.

61. P. Hitch and P. Clegg, Modes of referral of overseas immigrant and native born first admission to psychiatric hospital. Social Science and Medicine (1980) 14: 369-74; Baker, Psychosocial Problems of Refugees; Patrick and Heaf, Long Term Effect of War Related Deprivation on Health.

62. Ahmad and Smith, Humanitarian Action and Ethics.

63. U. Eziefula, Refugee women in the UK: Factors affecting engagement with mental health services. PhD thesis, Canterbury Christchurch University, 2012; V. Patel, H. Minas, A. Cohen and M. Prince, Global Mental Health. Oxford: Oxford University Press, 2014.

64. Ahmad and Smith, Humanitarian Action and Ethics.

65. Eziefula, Refugee women in the UK.

66. Baker, Psychosocial Problems of Refugees; Eziefula, Refugee women in the UK.

67. Eziefula, Refugee women in the UK.

68. M. Picinelli and G. Wilkinson, Gender differences in depression: Critical review. British Journal of Psychiatry (2000) 177: 486-92.

69. Baker, Psychosocial Problems of Refugees.

70. Hitch and Clegg, Modes of referral.

71. McColl and Johnson, Characteristics and needs of asylum seekers and refugees.

72. Healey, Refugee employment experiences; Turner, Bowie, Dunn, Shapo and Yule, Mental health of Kosovan Albanian refugees.

73. Ager and Strang, The Experience of Integration.

74. Baker, Psychosocial Problems of Refugees.

75. Healey, Refugee employment experiences. 
76. Baker, Psychosocial Problems of Refugees.

77. Ibid.

78. BBC, Bearing witness to the Holocaust. BBC News, 25 January 2001, http://news.bbc.co.uk/1/hi/uk/1133227 .stm.

79. BBC, Bearing witness; Helen Bamber quoted in L. Gray, You Have breath for No More Than 99 Words: What Would They Be? London: Darton, Longman \& Todd, 2011.

80. N. Belton, The Good Listener: Helen Bamber, a Life against Cruelty. London: Weidenfeld \& Nicolson, 1998.

81. Bamber quoted in Gray, No More Than 99 Words.

82. Ibid.

83. Giacco, Matanov and Priebe, Providing mental healthcare to immigrants.

84. Dillon and Smith, Life in the UK Test Handbook; Summerfield, Asylum seekers.

85. Healey, Refugee employment experiences. 